\title{
SISTEM INFORMASI MANAGEMEN COMPLAIN SERVICE CENTER DALAM MENINGKATKAN PELAYANAN TERHADAP CUSTOMER BERBASIS CRM DI GALLERY SMARTFREN KUNINGAN
}

(Studi Kasus : Gallery Smartfren Kuningan)

\author{
Meri Siti Maryam \\ Fakultas Ilmu Komputer Universitas Kuningan \\ Jalan Tjut Nyak Dhien No. 36 A Cijoho Kuningan Jawa Barat 45513 Telepon (0232) 2875097 \\ 2012091078@student.uniku.ac.id
}

Dunia bisnis industri telekomunikasi yang terus berkembang tentunya aspek pelayanan menjadi salah satu ujung tombak perusahaan telekomunikasi dalam meraih sebuah kesuksesan pasar konsumen. Namun sering kali terjadi masalah dalam hal pelayanan terhadap konsumen sama halnya yang terjadi di Gallery Smartfren Kuningan sering terjadi pada setiap harinya konsumen yang datang ke gallery smartfren untuk mengkonsultasikan permasalahan yang dihadapi oleh konsumen tersebut dari mulai konsultasi jasa pelayanan hingga kebutuhan akan perbaikan atau hard service, dalam hal ini sering kali pegawai di gallery mengalami kendala dikarnakan banyaknya konsumen yang harus dilayani dengan baik oleh pihak smartfren sedangkan jumlah pelayan terbatas. Tentu nya karna keterbatasan tersebut konsumen sering kali melakukan Complain kepada pihak smartfren dikarnakan ketidakpuasan pelayanan. Untuk menghindari hal tersebut maka diperlukan suatu system managemen complain yang lebih efektif agar setiap konsumen yang memerlukan jasa pelayanan di gallery smartfren dapat dilayani dengan baik dan tepat waktu. Salah satu bentuk metode yang digunakan untuk mengatasi permasalahan tersebut adalah metode CRM atau yang dikenal dengan Customer Relation Management. Salah satu penerapan CRM yang termasuk dalam kategori ini adalah dalam bentuk sms gateway.

Kata Kunci : Metode Customer Relationship Management, SMS GATEWAY

The business world of the industry continues to grow to be part of one of the spearheads of telecommunication companies in an effort to realize the consumer market. Everyone present at the Kuningan Smartfren Gallery often happens to everyone who comes to the gallery to find people who want to access the hard service, in this case often in the gallery traversed by consumers who should be handled well by the smartfren while the number of waiters limited. The answer is that consumers often do complain to the party smartfren dikarnakan service dissatisfaction. To avoid these things then the management system will provide more effective complaints for every consumer who can access properly and on time. One form of method used to discuss the problem is the CRM method or known as Customer Relations Management. One of the implementation of CRM that fall into this category is in the form of sms gateway.

Keywords: Customer Relationship Management Method, SMS GATEWAY

\section{PENDAHULUAN}

1.1 Latar Belakang Masalah

Dalam dunia bisnis industri telekomunikasi yang terus berkembang tentunya banyak hal yang harus diperhatikan oleh para pelaku bisnis, persaingan tentunya sudah menjadi bagian yang mutlak terjadi di dunia bisnis industri telekomunikasi, salah satu aspek dari persaingan di dunia bisnis industri telekomunikasi adalah aspek service / pelayanan. 
Aspek pelayanan menjadi salah satu ujung tombak perusahaan telekomunikasi dalam meraih sebuah kesuksesan pasar konsumen, ini dikarenakan semakin baik tingkat pelayanan yang diberikan kepada konsumen dari pelayanan jasa atau pelayanan kualitas maka konsumen akan semakin loyal terhadap produk dari perusahaan telekomunikasi tersebut.

Namun seringkali terjadi masalah dalam hal pelayanan terhadap konsumen, kondisi ini sering terjadi dimana pelayanan yang diberikan kepada konsumen tidak mencapai Benefits Of Complain seperti yang di ungkapkan oleh D.M. Martin (1994) menyatakan bahwa: "Mature organizations encourage customers to complain. They seek to convert complaining customers into satisfied customers." Oleh karena itu, bagaimana organisasi pelayanan memanajemen komplain terhadap pelayanan konsumen akan memberikan dampak yang signifikan terhadap efektivitas pelayanan dan persepsi konsumen terhadapnya.

Sama halnya yang terjadi di Galery Smartfren Wilayah Kab.Kuningan, Managemen Komplain merupakan sebuah pelayanan bagi konsumen dari produk smartfren dimana gallery ini berfungsi sebagai service central smartfren dikabupaten kuningan.

Sering terjadi pada setiap harinya konsumen yang datang ke gallery smartfren untuk mengkonsultasikan permasalahan yang dihadapi oleh konsumen tersebut, dari mulai konsultasi jasa pelayanan hingga kebutuhan akan perbaikan atau hard service. Dalam hal ini seringkali pegawai di gallery mengalami kendala dikarenakan banyaknya konsumen yang harus dilayani dengan baik oleh pihak smartfren sedangkan jumlah tenaga pelayanan terbatas. Tentunya karena keterbatasan tersebut konsumen seringkali melakukan komplain kepada pihak smartfren dikarenakan ketidakpuasan pelayanan.

Untuk menghindari hal tersebut maka diperlukan suatu system managemen komplain yang lebih efektif agar setiap konsumen yang memerlukan jasa pelayanan di gallery smartfren dapat dilayani dengan baik dan tepat waktu.

Salah satu bentuk metode yang dapat digunakan untuk mengatasi permasalahan tersebut adalah dengan metode CRM atau yang dikenal dengan Costumer Relation Management, CRM adalah suatu jenis strategi perusahaan yang secara khusus membahas teori mengenai penanganan hubungan antara perusahaan dengan konsumennya dengan tujuan meningkatkan nilai perusahaan di mata para konsumennya. CRM juga dapat didefinisikan sebagai strategi atau pendekatan yang diterapkan suatu organisasi untuk mempelajari kebiasaan dan keperluan konsumen sehingga suatu organisasi memiliki hubungan yang lebih dekat ke konsumen. Terdapat juga pengertian lain dari CRM, dimana CRM didefinisikan sebagai sistem informasi yang terintegrasi yang digunakan untuk merencanakan, menjadwalkan, dan mengendalikan aktivitas-aktivitas prapenjualan dan pasca penjualan dalam sebuah organisasi.

Berdasarkan definisi tersebut terlihat bahwa CRM bukan hanya sebagai suatu teknologi yang diwujudkan dalam bentuk sistem informasi tetapi lebih tepatnya adalah suatu strategi perusahaan yang diwujudkan dengan bantuan teknologi dengan penekanan hubungan terhadap konsumen yang lebih baik. Hal ini senada dengan pernyataan Glen Petersen dalam bukunya "Roi: Building the CRM Business Case", dimana ia mengatakan "sistem CRM yang paling sukses 
ditemukan dalam organisasi yang menyesuaikan model bisnisnya untuk profitabilitas, bukan hanya merancang ulang sistem informasinya".

Oleh sebab itu penulis tertarik untuk melakukan pembahasan tentang “ Sistem Informasi Management Complain Service Center Dalam Meningkatkan Pelayanan Terhadap Customer Berbasis CRM Di Gallery Smartfren Kuningan "sebagai judul Skripsi ini..

\subsection{Identifikasi Masalah}

1. Pelayanan yang diberikan kepada konsumen di gallery smartfren belum mencapai tujuan yang diharapkan.

2. Belum adanya pemahaman dan implementasi operasional Costumer Relation Managemen untuk proses managemen complain terhadap pelayanan konsumen.

3. Banyaknya konsumen yang harus dilayani oleh pihak gallery smartfren membuat pelayanan terhadap konsumen kurang maksimal.

4. Kepastian akan waktu penyelesaian terhadap masalah konsumen belum terintegrasi dengan tepat sehingga menimbulkan ketidakapastian terhadap waktu penyelesaian kepada konsumen

\subsection{Batasan Masalah}

1. Sistem yang dibangun merupakan sistem peningkatan pelayanan terhadap konsumen dengan melakukan penerapan managemen komplain.

2. Penerapan managemen komplain yang dilakukan meliputi hal - hal yang bersifat pelayanan langsung terhadap konsumen yang berupa :

a. Pelayanan keluhan konsumen terhadap produk.

b. Pelayanan terhadap waktu penyelesaian dalam konteks perbaikan yang bersifat teknis. c. Pelayanan keluhan konsumen terhadap pelayanan jasa yang didasarkan karena kebutuhan informasi.

d. Informasi dan kebutuhan promosi yang diperlukan.

e. Estimasi waktu dalam pelayanan.

3. Sistem yang dibangun menggunakan bahasa pemograman Php dan Mysql sebagai database nya.

\section{METODOLOGI PENELITIAN}

\subsection{Teknik Pengumpulan Data}

1. Observasi

Observasi adalah alat pengumpulan data dengan cara yang dilakukan cara mengamati dan mencatat secara sistematik gejala-gejala yang diselidiki.

2. Wawancara

Wawancara adalah proses tanyajawab dalam penelitian yang berlangsung secara lisan dalam mana dua orang atau lebih bertatap muka mendengarkan secara langsung informasiinformasi atau keteranganketerangan.

3. Study Literatur Mencari informasi dari beberapa literature yang ada, baik dari referensi buku atau litelatur lain yang dapat dijadikan acuan dalam penyusunan sebuah karya ilmiah.

2.2 Metode Pengembangan Perangkat Lunak

Metode Waterfall disebut juga siklus klasik (1970-an) dan sekarang ini lebih dikenal dengan sekuensial linier yang membutuhkan pendekatan sistematis dan sekuensial dalam pengembangan s/w dan dimulai dari analisis, desain, coding, testing dan pemeliharaan. Sebagai contoh tahap desain harus menunggu selesainya tahap sebelumnya yaitu tahap requirement. Secara umum tahapan pada model waterfall dapat dilihat pada gambar berikut : 


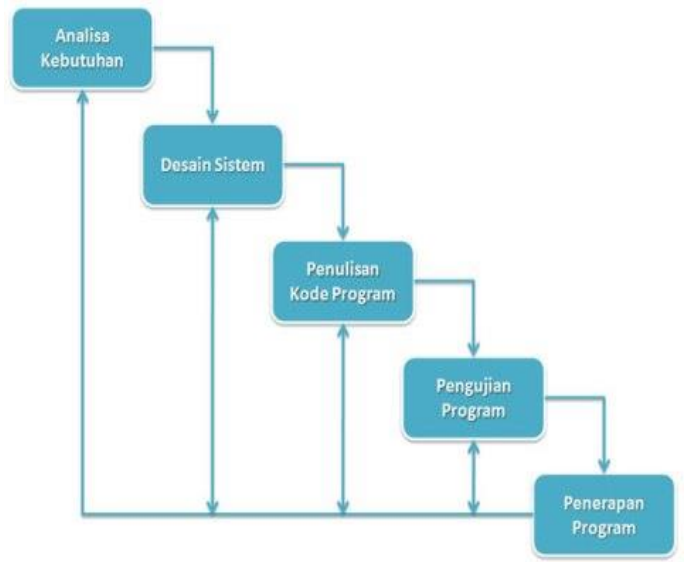

Gambar 1. Model Pengembangan Sistem Waterfall (Roger S. Pressman,2012)

Gambar di atas adalah tahapan umum dari model proses ini. Akan tetapi Roger S. Pressman memecah model ini menjadi 5 tahapan meskipun secara garis besar sama dengan tahapantahapan model waterfall pada umumnya. Berikut adalah penjelasan dari tahap-tahap yang dilakukan di dalam model ini menurut Pressman:

1. Analisa Kebutuhan

Pembentukan kebutuhan dari semua elemen sistem dan menganalisa kebutuhan keinginan pengguna. Meliputi I/O, waktu pengerjaan, ukuran dan jumlah data yang ditangani.

2. Desain Sistem

Proses menentukan arsitektur sistem secara total dan menentukan ukuran data dan jumlah data serta menentukan dasar-dasar pembentukan dan pemilihan struktur data, struktur program, arsitektur program, pemilihan algoritma, intereksi dengan pengguna.

3. Penulisan Kode Program

Mentrasformasikan desain kedalam baris-baris program, pemilihan bahasa. Tahap ini merupakan implementasi dari tahap design yang secara teknis nantinya dikerjakan oleh programmer.

4. Pengujian Program
Pengujian kebenaran program error debugging. Semua fungsi-fungsi software harus diuji cobakan, agar software bebas dari error, dan hasilnya harus benar-benar sesuai dengan kebutuhan yang sudah didefinisikan sebelumnya.

5. Penerapan Program.

Penerapan program ini difungsikan untuk menggunakan system yang telah dibangun dan melakukan Pemeliharaan suatu software diperlukan, perawatan s/w agar dapat digunakan terus.

\subsection{Tujuan Penelitian}

1. Meningkatkan pelayanan untuk memberikan informasi kepada konsumen agar mereka terus memberikan kepercayaanya kepada perusahaan komunikasi Smartfren.

2. Implementasi CRM (Costumer Relation Management) yang berguna untuk memberikan pelayanan yang memuaskan bagi konsumen.

3. Memudahkan pihak perusahaan komunikasi Smartfren dalam meningkatkan kepuasan konsumen.

\subsection{Costumers Relationship Management (CRM)}

Costumers Relationship Management (CRM) merupakan sebuah sistem informasi yang terintegrasi yang digunakan untuk merencanakan, menjadwalkan, dan mengendalikan aktivitas-aktivitas prapenjualan dan pasca penjualan dalam sebuah organisasi. CRM melingkupi semua aspek yang berhubungan dengan calon konsumen dan konsumen saat ini, termasuk di dalamnya adalah pusat panggilan (call center), tenaga penjualan (sales force), pemasaran, dukungan teknis (technical support) dan layanan lapangan (field service).

Costumers Relationship Management (CRM) diawali dengan pengumpulan 
informasi tentang apa yang dibutuhkan dan diharapkan oleh konsumen dari perusahaan. Dengan mengetahui kebutuhan dan harapan dari konsumen tersebut, perusahaan dapat memanjakan dan "mengikatnya" dalam sebuah "persahabatan". Menurut konsepnya CRM mengajurkan agar perusahaan membuka saluran-saluran komunikasi semudah mungkin dengan tingkat respon yang tinggi, agar konsumen merasakan kedekatan dengan pihak perusahaan. Dari situ, loyalitasnya terhadap perusahaan sedikit demi sedikit akan menjadi tumbuh dan berkembang. Dengan demikian perusahaan akan memperoleh manfaat dari penerapan CRM ini, yakni memilki konsumen yang loyal.

Adapun Manfaat dari CRM itu sendiri adalah sebagai berikut:

1. Jumlah konsumen bertambah, yaitu mencari konsumen baru disamping tetap memelihara tingkat kepuasan konsumen yang sudah ada.

2. Mengetahui tingkat kepemilikan perusahaan pada konsumen, yaitu dengan mengetahui kebutuhan konsumen.

3. Mengetahui kebutuhan konsumen pada masa yang akan datang, yaitu melalui hasil transaksi.

4. Mengetahui perbaikan yang harus dilakukan pada service yang diberikan kepada konsumen.

5. Mampu menganalisis pola data transaksi, sebagai contoh mampu mengetahui kombinasi produk yang akan dijual pada waktu-waktu tertentu.

6. Mengurangi resiko operasional, yaitu dengan mengetahui prediksi yang akan terjadi dan kesalahan yang pernah dilakukan melalui customer history.

\section{HASIL DAN PEMBAHASAN}

Berdasarkan analisa dari sistem yang ada, maka diusulkan suatu program Implementasi CRM dalam meningkatkan kepuasan konsumen Smartfren Pada proses perancangan sistem yang akan dibangun, dibuat dengan menggunakan beberapa bentuk rancangan yaitu Data Flow Diagram (DFD), Entity Relationship Diagram (ERD), desain tabel, desain input dan desain output.

3.1 Diagram Konteks

Diagram konteks dibuat untuk menggambarkan sumber serta tujuan data yang akan diproses atau dengan kata lain diagram tersebut digunakan untuk menggambarkan sistem secara umum/global dari keseluruhan sistem yang ada.

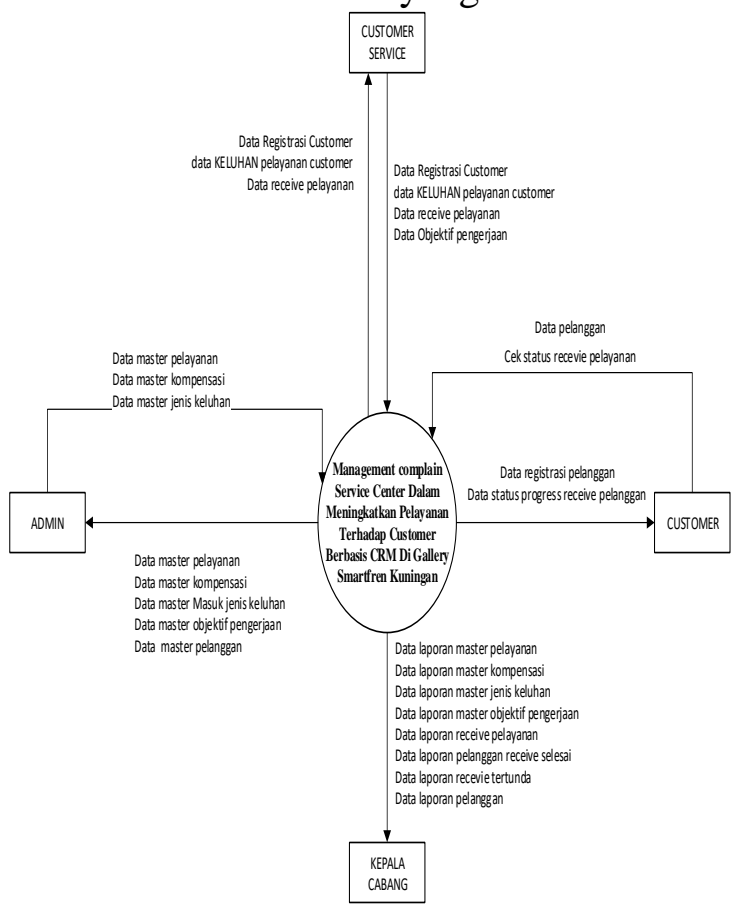

Gambar 3. Diagram Konteks Management Complain

\subsection{DFD Level 0}

Data Flow Diagram merupakan gambaran sistem secara logika tanpa mempertimbangkan lingkungan fisik dimana data tersebut mengalir atau disimpan. DFD merupakan alat yang dapat mengambarkan arus data di dalam 
sistem secara terstruktur dan jelas. Berikut adalah DFD level 0 :

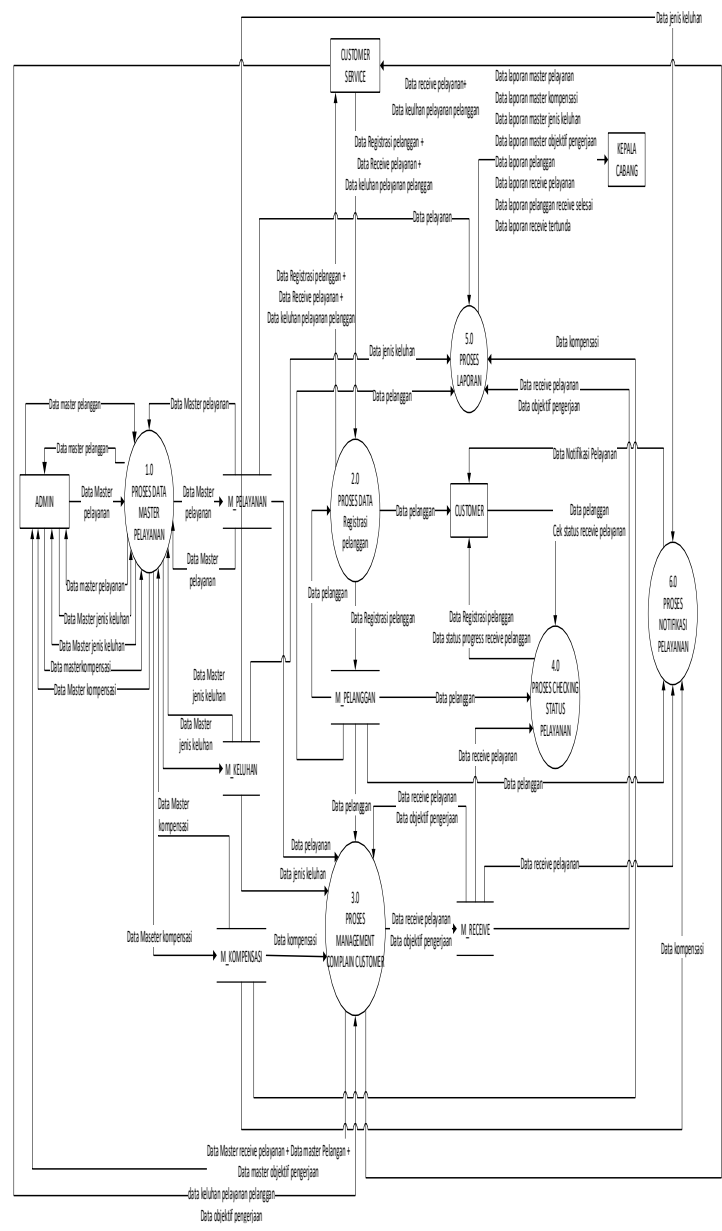

Gambar 4. DFD Level 0

Penjelasan :

1. Admin akan menginputkan data master data untuk pelayanan pada proses 1.0 dan menyimpannya didalam database sistem.

2. Customer Service akan memberikan data registrasi pelanggan sebagai kunci untuk mengakses progress pelayanan kedalam sistem sesuai dengan pencatatan pelayanan.

3. Admin akan mengupdate status pengerjaan layanan terhadap pelanggan melalui sistem dimana progress ini didasarkan pada kelanjutan pengerjaan yang dilakukan oleh pihak smartfren

4. Pelangganakan mengecek progress pengerjaan pelayanan melalui akses web portal yang disediakan pada sisi client.

5. Kepala cabang akan mengakses laporan - laporan dari hasil pengolahan data yang dilakukan admin sebagai bentuk pengawasan dan pertanggungjawaban structural management di perusahaan.

\subsection{DFD Level 1}

Pada level 1 ini dijelaskan bagaimana terjadinya proses pelayanan terhadap konsumen berdasarkan :

1. Pelayanan keluhan konsumen terhadap produk,

2. Pelayanan terhadap waktu penyelesaian dalam konteks perbaikan yang bersifat teknis,

3. Pelayanan keluhan konsumen terhadap pelayanan jasa yang didasarkan karena kebutuhan informasi,

4. Informasi dan kebutuhan promosi yang diperlukan dan

5. Estimasi waktu dalam pelayanan.

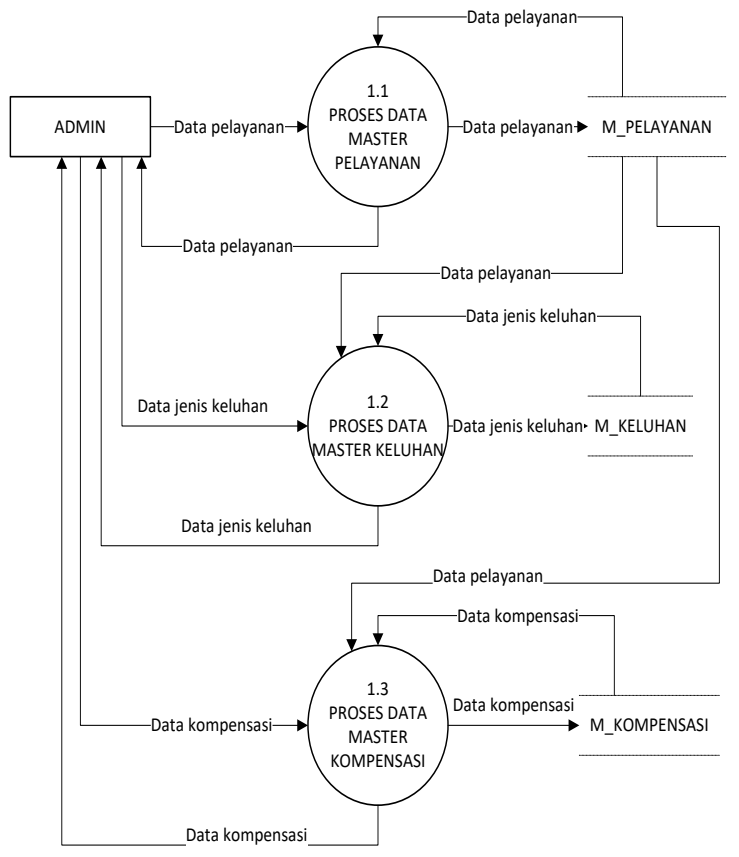

Gambar 5. DFD Level 1 Proses Pemasteran 


\subsection{Entity Relationships Diagram /} ERD

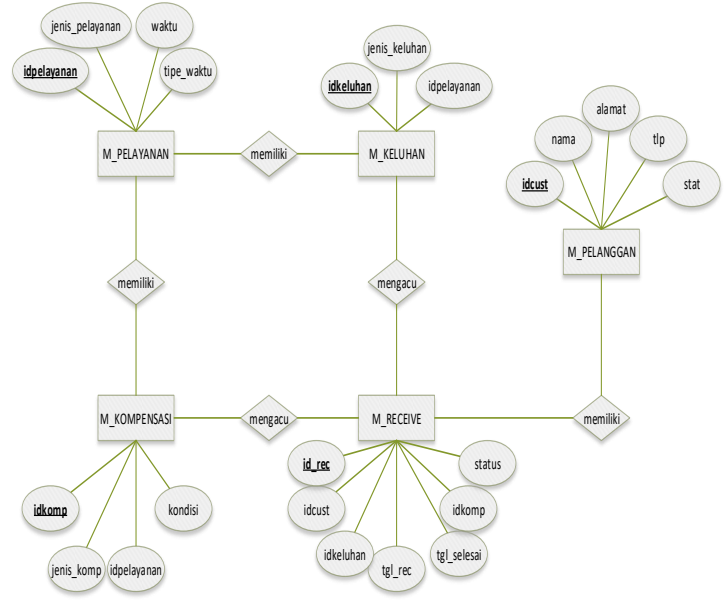

Gambar 6. ERD Sistem CRM (Customer Relationship Management) Dalam Meningkatkan Kepuasan Konsumen

\subsection{Rancangan Backend Admin}

\section{Form Login}

Form login digunakan oleh admin untuk login tehadap sistem. Dimana pada form ini data admin akan divalidasi berupa username dan password. Apabila password tidak valid maka sistem akan menampilkan data tidak valid.

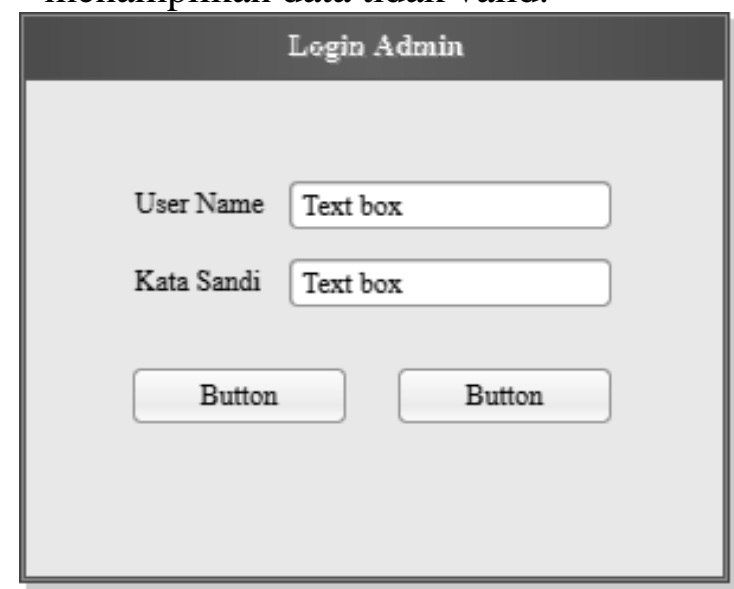

Gambar 7. Form Menu Login

2. Proses Kelola Input Data Konsumen Pada proses ini admin akan melakukan penginputan data konsumen kedalam system sebagai pelanggan aktif yang ter-registrasi yang kemudian akan memiliki hak sebagai user, jika terdapat konsumen baru maka admin akan menambahkan konsumen baru tersebut di form tambah konsumen.
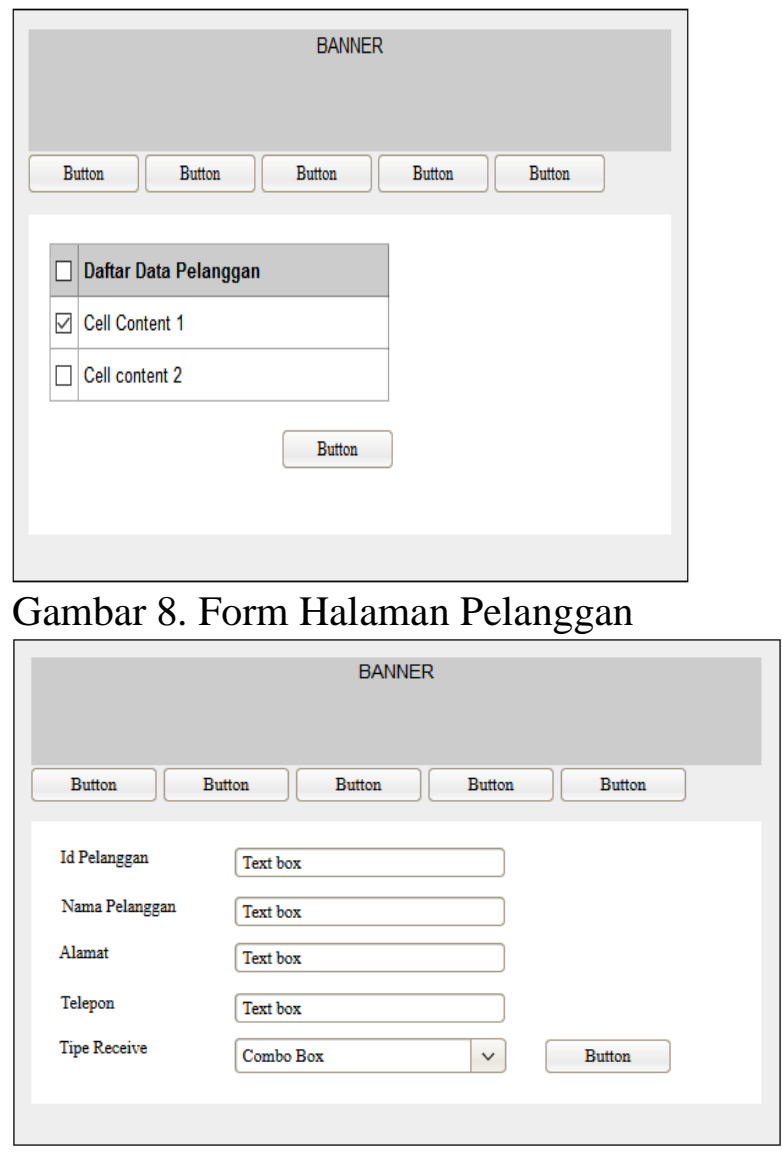

Gambar 9. Form Penambahan Konsumen Baru

\section{KESIMPULAN}

Implementasi metode CRM untuk Sistem Informasi Management Complain Service Center Dalam Meningkatkan Pelayanan Terhadap Customer Berbasis CRM Di Gallery Smartfren Kuningan Dengan Menggunakan PHP Dan Mysql ini dirasakan cukup dibutuhkan, karena mempermudah dalam pengelolaannya. Adapun beberapa hal yang dapat disimpulkan antara lain :

1. Pihak management perusahaan dapat melakukan proses pelayanan terhadap konsumen secara lebih sistematis dan efisien. 
2. Customer Service dapat lebih mendapatkan kemudahan yang multi point terhadap kebijakan dalam hal pelayanan terhadap pelanggan yang dibuat perusahaan dan akan mempermudah pengguna untuk menjalani proses pelayanan di gallery smartfren.

3. Melalui penggunaan metode CRM ini dapat melihat tingkat kepuasan pelanggan berdasarkan kemudahan yang didapatkan dan kejelasan informasi sehingga kedepannya pihak perusahaan akan mampu menajalankan kompetensi kemampuan yang baik.

\section{SARAN}

1. Diperlukannya pengembangan system yang lebih mendalam guna meningkatkan pelayanan pelanggan, dimana data yang akan diolah dan prosedur penggunan system akan dapat dilakukan dengan lebih cepat.

2. Diperlukannya tenaga IT yang mempuni untuk dapat mendukung system ini.

3. Pihak perusahaan diharapkan mampu melakukan pengembangan sistem pelayanan pelanggan secara terkomputerisasi agar memudahkan operasional dalam melakukan simulasi ini.

\section{DAFTAR PUSTAKA}

Bin Ladjamudin, Al-Bahra. (2005).

Analisis dan Desain Sistem Informasi. Yogyakarta : Graha Ilmu.

Rizky, Soetam. (2011). Konsep Dasar Rekayasa Perangkat Lunak. Jakarta : Prestasi Pustaka.

Ladjamuddin B, Al-Bahra. (2006). Rekayasa Perangkat Lunak. Yogyakarta : Graha Ilmu

Pressman, RS. (2012). Rekayasa Perangkat Lunak Pendekatan
Praktisi (Buku Satu). Yogyakarta: Andi.

Whitten JL, Bentley LD, Dittman KC. (2004). System Analysis and Design Methods. Diterjemahkan oleh: Tim Penerjemah Andi. Yogyakarta: Andi.

Buttle,

Francis.

(2004).CustomerRelationshipMan agement(Manajemen Hubungan Pelanggan), Concepts and Tools, Elsier Ltd.Dialihbahasakan oleh AriefSubiyanto, Bayumedia Publishing, 2007.

Madcoms. (2011). Dreamweaver CS5 PHP MySQL untuk pemula. Yogyakarta : ANDI 